\title{
Inovação em Serviços no Paradigma da Economia do Aprendizado: a Pertinência de uma Dimensão Espacial na Abordagem dos Sistemas de Inovação
}

\author{
Eduardo Raupp de Vargas \\ Paulo Antônio Zawislak
}

\begin{abstract}
RESUMO
A análise do processo de inovação em serviços é recente na literatura, onde este foi tradicionalmente considerado um processo decorrente das inovações engendradas na indústria. Destacam-se, nesta perspectiva, três abordagens: a tecnicista, baseada nos serviços, e a integradora. Esta última, em especial, destaca-se pela tentativa de estabelecer uma teoria única da inovação, que contemple tanto a indústria quanto os serviços, constituindo as conceituações necessárias para diferenciar suas especificidades. Neste sentido, este artigo procura investigar as bases teóricas para a aplicação da abordagem dos sistemas de inovação sobre o processo de inovação em serviços e, em especial, a consideração de uma dimensão espacial, local ou regional, a ser considerada em futuras investigações empíricas. Nossas considerações apontam na direção da pertinência deste enfoque, uma vez que o processo de aprendizagem, determinante do processo de inovação sob o novo paradigma, possui caráter delimitado geográfica, cultural e setorialmente, que está na fonte das vantagens competitivas das organizações.
\end{abstract}

Palavras-chave: inovação em serviços; sistemas de inovação; aprendizagem.

\begin{abstract}
The analysis of innovation in services is recent in literature once this kind of innovation has for long been considered as a byproduct from innovation in manufacturing. Three approaches deserve more attention under this perspective: the technicist, the service-based and the integrated. The latter attempts to establish a single theory of innovation for manufacturing and services, including the necessary conceptualizing to distinguish their specificity. In this sense, this paper aims at investigating theoretical foundations for the application of the innovation systems approach to services, including a spatial, local or regional dimension in future empirical studies. The paper argues for the relevance of this approach once the learning process, decisive for the innovation process in the realm of the new paradigm, is related to geographical, cultural and sectoral boundaries that provide a source for competitive advantage for the organizations.
\end{abstract}

Key words: service innovation; innovation systems; learning. 


\section{INTRODUÇÃO}

Um conjunto de transformações sociais, políticas e econômicas marcou as décadas que encerraram o século XX. Estas mudanças trazem em seu cerne a decadência do modelo fordista e de suas principais instituições: a grande empresa verticalizada, a produção padronizada em massa e o grande número de trabalhadores assalariados. Em seu lugar emerge um processo de horizontalização das empresas, de priorização de suas competências centrais e a busca da cooperação como ferramenta estratégica na busca de ativos complementares que viabilizem o alcance de vantagens competitivas sustentáveis. Ao mesmo tempo, o advento das chamadas tecnologias da informação repercute em mudanças drásticas em todos os campos industriais e altera de forma substancial o processo produtivo. Esses processos são interligados, retroalimentados e constituem a base técnica e organizacional do chamado processo de globalização, o qual se complementa com a velocidade e intensidade de integração dos mercados financeiros. Este conjunto de mudanças estabelece novo paradigma, denominado de "economia do aprendizado", onde a aprendizagem assume o papel de principal processo e o conhecimento, em especial aquele tácito, inimitável, passa a ser o principal ativo na dinâmica organizacional em busca de vantagens competitivas sustentáveis.

Neste paradigma, outro traço marcante reside na alteração da divisão setorial da atividade produtiva, com os serviços adquirindo uma importância relativa superior à indústria na composição da riqueza nacional das principais economias desenvolvidas. Esta importância, entretanto, não se reflete no tratamento atribuído aos serviços na literatura, especialmente no que tange à sua capacidade inovadora. De forma recorrente os serviços são encarados como um setor reflexo, cuja dinâmica seria dependente dos movimentos da indústria e, neste sentido, incapaz de autonomamente sustentar o crescimento de longo prazo de uma região ou país.

Para enfrentar este paradoxo, vários esforços têm sido recentemente levados a termo para afirmar o setor de serviços na análise econômica e nos estudos organizacionais, especialmente no que diz respeito à teoria da inovação. Este artigo se insere neste caminho, propondo a discussão da pertinência da análise do processo de inovação em serviços, sob a abordagem dos sistemas de inovação e, em especial, da consideração de uma dimensão espacial, local, regional ou nacional, nesta abordagem, uma vez considerada a centralidade do processo de aprendizagem para a compreensão da dinâmica desses sistemas. Duas questões 
estão subjacentes a este debate. Por um lado, até que ponto a abordagem dos sistemas de inovação, inicialmente desenvolvida para explicar o processo de inovação no setor manufatureiro, pode ser aplicada ao setor de serviços, respeitando a heterogeneidade e as peculiaridades deste setor. Por outro, em que medida estas especificidades, consideradas à luz do processo de mudança de paradigma, anteriormente descrito, permitem identificar alguma lógica espacial ou, em outras palavras, alguma demanda de proximidade, que interfira no processo de inovação. As especificidades do setor de serviços e o papel do processo de aprendizagem na evolução dos sistemas de inovação nos parecem os elementos centrais para este debate.

Nosso objetivo é, portanto, a partir da revisão da literatura, reunir os elementos que permitam o esboço de um modelo teórico de análise do processo de inovação em serviços, sob o enfoque dos sistemas de inovação, a ser futuramente posto à prova pela investigação empírica. Para tanto este artigo está organizado em quatro sessões, além desta introdutória e de nossas considerações finais. Inicialmente, propomos uma revisão das principais abordagens teóricas sobre a inovação em serviços. Em seguida, apresenta-se a origem histórica e as principais contribuições da abordagem dos sistemas de inovação, ressaltando o papel do processo de aprendizagem na dinâmica desses sistemas. Na terceira seção, analisamos algumas tentativas recentes de articular estas duas vertentes, ou seja, de aplicar abordagens sistêmicas ao setor de serviços, tendo em conta suas especificidades. Na quarta seção, discutimos os limites destas iniciativas e os primeiros elementos para a formulação de um modelo de análise dos sistemas de inovação em serviços, contemplando sua dimensão espacial. Nossa discussão aponta para a necessidade de um enfoque dos sistemas de inovação sob o prisma setorial, como forma de assegurar a compreensão das especificidades dos setores de serviços, considerando, entre elas, a questão da dimensão espacial. Por fim, à guisa de conclusão, teceremos nossas considerações finais.

\section{Teoria da Inovação em Serviços}

O debate teórico acerca da inovação em serviços é bastante novo e controverso. Por um lado, autores se debruçam sobre a validade de se trabalhar com o conceito de inovação em organizações do setor de serviços. Isto é, debatem se o setor de serviços possui a capacidade de gerar inovações endogenamente ou, caso contrário, se as mudanças verificadas são subprodutos de processos de inovação originários da indústria. Por outro lado, onde esta discussão se encontra superada, emerge um segundo ponto: a conveniência de uma teoria específica para a inovação em serviços. Ou seja, considerando que as organizações do setor de 
serviços inovam, em que medida este processo guarda especificidades em relação ao verificado na manufatura e que, portanto, mereçam uma explicação diferenciada.

De forma sintética, como aponta Gallouj (1998), as várias respostas presentes na literatura a estas duas questões conformam as principais abordagens teóricas sobre a inovação em serviços, como se explicita em seguida.

\section{a) A abordagem tecnicista}

A abordagem tecnicista é a que domina a maioria dos estudos empíricos sobre inovação em serviços efetuados até hoje. Baseia-se na concepção de que a inovação em serviços é resultado da adoção de inovações tecnológicas desenvolvidas no setor de produção de bens de capital. Assim, a análise da inovação em serviços não seria a análise de um processo de inovação em si, mas a apreciação do processo de difusão de inovações tecnológicas da indústria no setor de serviços.

A principal tentativa de sistematização desta abordagem foi proposta por Barras (1986). Em seu modelo do "ciclo reverso do produto", Barras sustenta que a inovação em serviços percorreria um ciclo ao contrário do verificado nas inovações tecnológicas. No primeiro momento, a introdução de nova tecnologia, ao invés de causar impacto radical e lucros extraordinários, no sentido schumpeteriano, levaria apenas ao aumento da eficiência na prestação de serviços existentes. Seria, portanto, uma fase inicial de inovações incrementais destinadas à melhoria da eficiência. No segundo estágio do ciclo, Barras aponta que as inovações seriam ainda incrementais, mas já voltadas para melhorias na qualidade do serviço. No estágio final, quando o processo de difusão tecnológica estaria em sua fase mais avançada, então a tecnologia levaria à constituição de novos serviços (inovações radicais) ou recombinações de serviços já existentes.

Embora seu propósito, explicitado no título do seu artigo, tenha sido o de constituir uma teoria da inovação em serviços, o modelo do "ciclo reverso do produto" acaba reforçando a concepção de que a indústria é o "locus" da inovação e os casos analisados reforçam sua caracterização como um modelo de análise, isto sim, dos impactos da tecnologia da informação sobre os serviços (Gallouj, 1998).

b) A abordagem baseada nos serviços

A abordagem baseada nos serviços procura ressaltar modalidades de inovação específicas do setor de serviços (em especial as chamadas inovações ad hoc definidas mais adiante). A constituição de novo serviço se dá por meio da instituição 
de um "serviço básico" ao qual podem estar associadas inovações incrementais em "serviços periféricos". Com o mesmo sentido, esta abordagem procura identificar e definir o que denomina trajetórias intangíveis dos serviços em contraposição às trajetórias tecnológicas.

A idéia central deste enfoque é que a relação usuário-produtor, principal característica distintiva das relações produtivas em serviços, mesmo tendo em conta as variações em seu grau de intensidade, de acordo com o ramo dos serviços considerado, oferece oportunidades para a inovação na elaboração de um serviço que superam qualquer processo de mera difusão de inovação tecnológica de processo ou de produto (Hauknes, 1998).

c) A abordagem integradora

Este enfoque se propõe a reconciliar bens e serviços, integrando-os definitivamente em uma única teoria da inovação. Mesmo ressaltando as especificidades dos serviços, a abordagem integradora considera que a inovação envolve características genéricas, em que a ênfase recairá sobre peculiaridades da manufatura ou dos serviços de acordo com a intensidade da relação usuárioprodutor verificada no mercado específico em análise. Conforme esclarece Hauknes (1998), esta abordagem sustenta que "existe um processo de convergência ao longo de um continuum entre a manufatura e os serviços" (Hauknes, 1998, p. 28). Como decorrência disto, estabelecem-se características funcionais que possam ser extensivas a produtos e serviços e, a partir delas, as tipologias das inovações que permitam abrigar indústria e serviços.

A apreciação destas abordagens leva a crer que as respostas aos questionamentos iniciais estão vinculadas, acima de tudo, ao conceito de inovação subjacente. Por exemplo, o conceito adotado pela abordagem tecnicista, que reduz a noção de inovação ao surgimento de um novo objeto técnico, cujo conhecimento está precisamente codificado a priori, desconsiderando as peculiaridades dos serviços, não permite uma análise adequada aos processos de mudança inerentes a este setor. Assim, seguindo a abordagem integradora, a análise da inovação em serviços deve pressupor um conceito de inovação bastante amplo, tipicamente schumpeteriano, cuja inovação pode ser identificada em uma das situações mencionadas abaixo (Schumpeter, 1985).

. Introdução de novo serviço ou de nova qualidade de serviço.

- Introdução de novo método para prestação de serviço, como, por exemplo, nova forma de entrega de serviço.

Abertura de novo mercado. 
. Obtenção de nova fonte de matéria-prima ou de insumos intermediários.

. Estabelecimento de nova forma de organização de uma determinada indústria em que a empresa que estamos analisando opere.

Na perspectiva exposta por Dosi (1982), essas situações arroladas por Schumpeter e, portanto, as atividades de inovação, podem ser entendidas como atividades inseridas num processo de resolução de problemas. Estes processos, por sua vez, estão contextualizados sob determinada estrutura técnica, cultural, social e econômica, enfim, sob determinado ambiente institucional. Por isso Gallouj (1997) procura estabelecer a relação entre paradigma tecnológico, ou paradigma tecnoeconômico, e inovação no setor de serviços.

A noção de paradigma tecnológico tem sua origem em Dosi (1982). Ele o define como “'modelo' ou 'padrão' de solução de problemas tecnológicos selecionados derivados das ciências naturais e sobre tecnologias materiais selecionadas" (p. 152). Esta noção foi ampliada por Freeman e Perez, ao proporem o conceito de paradigma tecnoeconômico, "devido às mudanças envolvidas irem além de trajetórias de engenharia específicas para tecnologias de produto e processo e afetarem a estrutura de custos dos insumos e as condições de produção e distribuição por meio do sistema" (Freeman \& Perez, 1988, p. 47). Os mesmos autores definem o atual paradigma como o paradigma tecnoeconômico da informação, em que os serviços ocupam importantes funções. Neste sentido, diz Gallouj (1997), devem ser analisados em sua relação com os demais setores da atividade econômica, em especial com a indústria, sob a ótica dos impactos que lhe são causados pelo atual paradigma tecnoeconômico, como faz a abordagem tecnicista, mas também pelo papel que os serviços jogam neste paradigma.

As inovações em serviços podem assumir inúmeras trajetórias entre as possibilidades oferecidas pelo ambiente institucional. Estas trajetórias, por sua vez, não se restringem a trajetórias tecnológicas, definidas por Dosi (1982) como os padrões geralmente adotados na solução de problemas e, portanto, os padrões do progresso técnico. O que Gallouj (1997) ressalta é a importância das inovações institucionais ou organizacionais, definidas como "mudanças nas regras que governam os modos de interação entre os indivíduos em uma firma ou organização" (p. 27). Estas inovações institucionais dariam origem a trajetórias institucionais ou organizacionais que, embora não estejam diretamente associadas com qualquer inovação tecnológica, guardam relação com o paradigma tecnoeconômico vigente (Lakschmanan, 1989). A combinação e evolução destas trajetórias são únicas, de acordo com as opções que as firmas estabelecem. Como esclarece Zawislak (1996), "o processo de resolução de problemas e, por 
consequiência, o processo de inovação são uma característica que irá mostrar-se diferente de uma firma para outra... que gera comportamentos diferentes e histórias individuais diferentes" (p. 329-330).

As forças que dirigem este processo podem ser externas ou internas. As forças externas, segundo Sundbo e Gallouj (1998b), estão relacionadas com as trajetórias institucionais, tecnológicas, gerenciais, sociais e profissionais que influenciam determinados serviços, além das relações específicas estabelecidas com os competidores, fornecedores, com o setor público e, especialmente, com os clientes. As forças internas, por sua vez, são estabelecidas pela existência, ou não, de estruturas formais dedicadas à inovação, pelo envolvimento dos trabalhadores no processo de mudança e pela integração do processo de inovação ao planejamento estratégico da organização. As diferentes formas como estas forças se podem combinar em cada situação específica determinará o padrão de inovação. Neste sentido, a inovação em serviços pode, enfim, ser tomada como processo de decisão endógena das organizações que compõem o setor e que reflete os matizes e componentes específicos que decorrem da própria natureza dos serviços.

Já quanto aos tipos de inovação em serviços verificados, segundo Sundbo e Gallouj (1998b), pode-se observar o que se explicita a seguir.

. Inovações de produto: relacionados com o fornecimento de novo serviço, como, por exemplo, novo seguro, nova linha de financiamento, oferta por um hospital do atendimento de nova especialidade médica.

- Inovações de processo: relacionados com a modificação de procedimentos prescritos para a elaboração/produção de um serviço (back office) ou nos procedimentos de atendimento do usuário/cliente e de entrega do serviço (front office).

- Inovações organizacionais ou gerenciais: relacionadas com a introdução de novas ferramentas gerenciais ou novos modelos de gestão.

- Inovações de mercado: relacionadas com a descoberta de novos mercados, com a identificação de nichos em um mesmo mercado ou, ainda, com a mudança de comportamento da organização no mercado em que ela se insere.

Entretanto um novo tipo de inovação deve ser considerado. Conforme salienta Hauknes (1998), a intensidade da relação usuário/produtor em serviços nos deve levar a considerar o usuário (ou cliente) como importante fonte de formação de competências. Neste sentido, ele prossegue, a inovação em serviços poderia ser considerada "um processo de generalização de capacidades obtidas nas relações 
específicas com o cliente" (p. 30). Sundbo e Gallouj (1998a) afirmam, no mesmo rumo, que o processo de inovação em serviços é essencialmente processo interativo, em que o provedor dos serviços mantém ligações internas e externas que conduzem à inovação. Neste processo, surge novo tipo de inovação, denominada inovação ad hoc (ou "adocrática" ou ainda contingencial), resultado de um processo de resolução de problemas do usuário através da co-produção do serviço. Sundbo e Gallouj (1998b) definem a inovação ad hoc como "a construção interativa (social) de uma solução (estratégica, organizacional, social, legal etc.) para um problema particular posto pelo cliente. Este tipo de inovação é co-produzida pelo cliente e pelo provedor do serviço. Ele não é reproduzível, a não ser indiretamente, por meio da codificação, da formalização de parte da experiência e da competência" (p. 5). Este tipo de inovação, segundo vários autores, é freqüente em serviços intensivos em conhecimento. Pode-se depreender, no entanto, que em toda a atividade de prestação de serviços haverá espaço para este tipo de inovação em maior ou menor grau, dependendo da intensidade da relação usurário-produtor e da especificidade do problema a ser resolvido.

\section{A Abordagem dos Sistemas de Inovação}

A análise do processo de inovação no setor de serviços, resguardadas as peculiaridades que ressaltamos anteriormente, não pode estar desvinculada de uma visão geral sobre o processo de inovação nas economias capitalistas contemporâneas. Sem dúvida, esta é a proposição subjacente à abordagem integradora da inovação em serviços, a qual apresenta elementos de um enfoque sistêmico, como na noção de forças internas e externas, condicionando o processo de inovação. Aliados a esta perspectiva apresentamos, nesta seção, a origem e os fundamentos das principais abordagens sistêmicas desenvolvidas. $\mathrm{O}$ fio condutor de nossa exposição está associado ao corte analítico destes enfoques: a dimensão espacial em face da dimensão setorial. Partimos do enfoque mais abrangente, ou espacial, que procura apreender o processo de inovação em sua dimensão nacional, embora permita desdobramentos regionais ou mesmo locais, e chegamos ao enfoque mais específico dos sistemas setoriais de inovação.

\section{Abordagens dos Sistemas de Inovação sob a Lógica Espacial}

A abordagem sistêmica surge da crítica ao chamado "modelo linear de inovação", que teve seu apogeu logo após a Segunda Guerra Mundial e que guarda, em sua formulação fortes relações com o padrão de organização do trabalho na era fordista (Freeman, 1995). Segundo a abordagem sistêmica, o 
modelo linear incorre em dois graves problemas em seus fundamentos principais. O primeiro deles é a crença de que o investimento em pesquisa e desenvolvimento (P\&D) é a fonte fundamental de possíveis inovações, ou seja, o processo de inovação está diretamente relacionado com o conhecimento codificado, formal, explícito. O segundo diz respeito ao caráter tecnocrático do modelo, devido ao conceito de que uma inovação consiste necessariamente em novo equipamento, em novo objeto técnico. Em suma, toda inovação teria necessariamente conhecimento formal incorporado.

Freeman (1995) demonstra, a partir do estudo comparativo dos sistemas nacionais de inovação do Japão, da Coréia do Sul e da antiga União Soviética, que a estruturação de forte base científica não é, per se, garantia de inovações. No entanto, em grande parte devido à facilidade de estabelecer medidas e comparações internacionais, o modelo linear se propagou nos meios acadêmicos e oficiais, não obstante as crescentes evidências empíricas de que “... o sucesso das inovações, sua taxa de difusão e os ganhos de produtividade a ela associados dependem de uma ampla variedade de outras influências tanto quanto de P\&D formal" (Freeman, 1995, p. 9).

O ponto de partida da abordagem sistêmica, em contraponto ao modelo linear, é o entendimento do processo de inovação como processo de caráter interativo, cujos aspectos técnicos guardam sua relevância óbvia, mas cujo fundamento está em seu caráter social (Lundvall, 1988; 1998), sendo a inovação o resultado de um processo de aprendizagem coletiva (Keeble \& Wilkinson, 1999).

Este processo, segundo Nelson (1988), é um processo evolucionário e apresenta dois elementos essenciais que definem sua natureza em economias capitalistas: a incerteza e o caráter parcialmente público da tecnologia. De um lado, a existência de múltiplas trajetórias tecnológicas possíveis de serem seguidas pelas firmas torna a incerteza uma característica inerente à atividade de inovação. Nas palavras do autor, "o que o sistema de inovação capitalista proporciona são múltiplas fontes de iniciativa e uma competição entre aqueles que colocam suas apostas sobre diferentes idéias" (Nelson, 1988, p. 313). A definição no mercado, a posteriori, das trajetórias de sucesso, aquelas efetivamente inovadoras, faz com que as firmas incorram, por definição, em altos custos de transação. Por outro lado, o caráter parcialmente público de alguns aspectos da tecnologia estabelece limites à apropriação dos ganhos possíveis com uma determinada inovação. Seguindo a análise de Schumpeter, Nelson (1988) aponta que em sua difusão a tecnologia gradativamente perde seu caráter proprietário em função de um maior domínio público de sua utilização. Este processo estabelece, ainda segundo o mesmo autor, três grandes benefícios para o sistema como um todo: o compartilhamento de custos, nova base para novas inovações e o equilíbrio 
competitivo. Ao mesmo tempo, isto pode desestimular o investimento privado em inovações, uma vez que parece estabelecer limites temporais para que as firmas usufruam os retornos deste investimento.

A consideração desses elementos constitui a base para a preocupação com uma análise sistêmica do processo de inovação. A redução da incerteza passa pela constituição de formas alternativas de governança em relação ao mercado, especialmente por meio de arranjos cooperativos entre os agentes envolvidos no processo. Estes agentes, notadamente empresas, universidades, centros de pesquisa, governos em suas esferas de poder respectivas, relações interfirmas, especialmente do tipo usuário-produtor, produziriam o conhecimento necessário, em grande parte tácito, para o processo de inovação, através de relações rotineiras conhecidas como learning-by-doing, learning-by-using e learning-by-interacting (Lundvall, 1998). Neste sentido, as instituições vigentes em determinado sistema, ao definirem os canais e códigos de comunicação entre estes agentes, condicionarão a complexidade e a velocidade do processo de aprendizagem e, com isso, o ritmo, a direção das inovações e, enfim, da própria evolução do sistema.

Os agentes do processo de inovação e as instituições, juntamente com o conjunto de hábitos, normas e regras de comportamento, caracterizam determinado sistema de inovação (Lundvall, 1988; 1998). Sua dimensão espacial, por sua vez, estaria embasada no caráter diferenciado que estes sistemas apresentam, em geral em nível nacional. Alguns autores têm defendido que, sob o atual cenário internacional, uma espécie de tecnoglobalismo estaria reduzindo o significado de políticas nacionais de desenvolvimento tecnológico, à medida que a dinâmica das atividades inovadoras seria definida em escala global, conforme evidenciariam as alianças estratégicas e a descentralização dos esforços de P\&D das transnacionais (Lastres, Cassiolato, Lemos, Maldonado, \& Vargas, 1998). Entretanto, segundo Lundvall (1988), embora o processo de aprendizagem seja fenômeno global, caracterizando o paradigma da economia do aprendizado, aspectos institucionais, culturais e geográficos interferem no fluxo das relações usuário-produtor, e de outras relações rotineiras de aprendizagem no âmbito de determinado sistema, explicando a existência de peculiaridades de nível espacial, prioritariamente de nível nacional, mas também de níveis regionais ou locais. Além disso, ressalta que "a forma específica pela qual um sistema nacional está inserido na economia internacional é a chave para o entendimento de sua dinâmica interna. Meu ponto é que é legítimo e importante fazer progressos na análise de sistemas nacionais" (Lundvall, 1998, p. 414).

\section{O Conceito de Sistema Setorial de Inovação}

O conceito de sistema setorial de inovação é um componente do conceito de 
sistema setorial de inovação e produção proposto por Franco Malerba (2002, 2004). Em suas palavras, "um sistema setorial de inovação e produção é um conjunto de novos e estabelecidos produtos para usos específicos e o conjunto de agentes, levando a cabo interações mercadológicas e não-mercadológicas para a criação, produção e venda destes produtos" (Malerba, 2002, p. 50).

Malerba alinha os elementos que constituiriam os building blocks de um sistema setorial: a base de conhecimento e o processo de aprendizagem; as tecnologias básicas, os insumos e a demanda; os agentes do sistema e a formação da estrutura setorial; as instituições e, finalmente, os processos de geração de variedade e de seleção.

A análise da base de conhecimento, explícito e tácito considerados conjuntamente, é considerada por Malerba um elemento central para a definição de um setor. Não só pela existência de um determinado estoque de conhecimento setorial, mas pelo padrão de acessibilidade ao conhecimento externo da firma e pela possibilidade de acumulação de conhecimento, ou seja, em que grau o novo conhecimento gerado no setor se deve ao conhecimento já estabelecido. Em outras palavras, podemos dizer que os setores seriam diferenciados segundo determinado estoque de conhecimento identificado e pelas dinâmicas do processo de aprendizagem e do processo de apropriação do conhecimento, intimamente relacionados.

Os setores podem ser acentuadamente diferentes, ainda em termos das tecnologias em uso e perfil da demanda. Para cada setor, afirma Malerba (2002), há uma relação verificada entre seus produtos e, portanto, sua demanda, e as tecnologias necessárias para sua produção.

Os agentes fundamentais do sistema setorial, por sua vez, são as firmas, envolvidas nas atividades de produção e inovação. Estas se relacionam nos moldes das relações usuário-produtor de Lundvall (1988). Estas relações, tipicamente verticais, associadas às relações horizontais, possuem graus de importância variados entre os setores, constituindo também elementos de distinção intersetorial. Às relações interfirmas precisamos adicionar considerações sobre as relações com as organizações não-empresariais, ou sem fins lucrativos, tais como universidades, agências de regulação, governos instituições de financiamento e associações empresariais, entre outros, que colaboram na definição dos contornos reais do sistema setorial. Embora este conjunto de relações possa apresentar, $a$ priori, características típicas em determinado espaço geográfico considerado, esta questão não é vista como possível determinante da lógica setorial.

Já as instituições são definidas como "normas, rotinas, hábitos comuns, práticas estabelecidas, regras, leis, padrões e outros elementos, que delimitam a cognição 
e ação dos agentes e afetam as interações entre os agentes" (Malerba, 2002, p. 257). As instituições estabelecem marcas características a um setor pelo que, obviamente, conclui Malerba, marcas distintivas importantes entre os setores.

O processo de geração de variedade refere-se ao desenvolvimento de novas tecnologias, novos produtos, surgimento de novas firmas e instituições, bem como a adoção de novas estratégias e comportamentos. A diversidade que este processo gera está relacionada diretamente com a base de conhecimento e, por sua vez, se manifesta na própria estrutura de concentração setorial, no ritmo e trajetórias de inovação, bem como na natureza dos agentes que passam a surgir ou integrar o setor.

O processo de seleção, em direção complementar, vem reduzir a heterogeneidade, ao selecionar as firmas que perecerão e aquelas que evoluirão. Em outras palavras, estabelece parâmetros para evolução setorial, segundo determinados tipos de firmas, produtos, processos, estratégias, tecnologias e assim por diante. Este processo pode atuar via mercado, onde se destacaria o perfil da demanda como parâmetro de seleção, ou pela via institucional, em setores onde o marco regulatório possui influência notória.

Portanto, os processos de geração de variedade e de seleção estabelecem diferenciações de dois níveis entre os sistemas setoriais: diferenciações extensivas, no primeiro caso, diagnosticadas pela ampliação do número de agentes no setor, e intensivas, no segundo caso, caracterizadas pela preponderância de determinados padrões ao longo da evolução do setor.

\section{A Abordagem dos Sistemas de Inovação e Suas Aplicações ao Setor de Serviços}

Vários trabalhos têm abordado a pertinência do estudo da inovação em serviços sob a perspectiva da análise de sistemas de inovação (Hauknes, 1996; Hauknes, 1998; Sundbo \& Gallouj, 1998a, Sundbo \& Gallouj, 1998b). A abordagem integradora, apresentada na primeira seção, relacionando as forças que influenciam o processo de inovação, reforça a percepção de que a inovação em serviços, como na manufatura, possui uma lógica sistêmica. Nesta seção pretendese apresentar, de acordo com a literatura revisada, em que medida a perspectiva dos sistemas de inovação é aplicável para análise do setor de serviços. Duas abordagens, assentadas em resultados empíricos, são destacadas aqui: por um lado, a análise de Sundbo e Gallouj (1998a), inserida no que denominamos anteriormente de lógica espacial da abordagem dos sistemas de inovação, segundo 
a qual os autores identificam os sistemas de inovação em serviços como sistemas adocráticos; e, por outro lado, a aplicação do conceito de sistema setorial de inovação ao setor de serviços, empreendida por Tether e Metcalfe (2004).

\section{Sistemas de Inovação em Serviços como Sistemas Adocráticos}

Sundbo e Gallouj (1998a) consideram que um sistema de inovação pode ser entendido como "um padrão geral que pode descrever as atividades de inovação em um setor, neste caso no setor de serviços" (p. 18). Tal sistema poderia apresentar, segundo estes autores, duas configurações genéricas, explicitadas a seguir.

a) Sistemas de inovação institucionais: onde as relações entre os atores do sistema seguem certos padrões. Em especial, as relações de cooperação estão formalizadas por meio de contratos de longo prazo ou de normas tácitas difundidas ao longo do tempo e plenamente reconhecidas por todos.

b) Sistemas de inovação 'adocráticos' ${ }^{(1)}$ : alternativamente, as relações neste tipo de sistema não podem ser explicadas por leis, regras ou norma. “... é composto de certos atores, certas trajetórias de desenvolvimento dentro de importantes campos como tecnologia, administração, etc e algumas formas de comportamento que são comuns para o setor em análise" (p. 18). As ações em seu âmbito são guiadas por trajetórias gerais e as relações de cooperação são pontuais. É um sistema voltado mais para a competição no mercado e menos para a constituição de mercados organizados, nos termos de Lundvall (1988).

A partir da análise de evidências empíricas ${ }^{(2)}$ sobre os padrões típicos de inovações verificados em serviços, os autores concluem que não há um sistema de inovação para o setor de serviços em geral. Entretanto consideram que, embora poucos subsetores de serviços apresentem trajetórias coerentes, há a predominância de determinados padrões de inovação, em especial de um padrão de gestão estratégica da inovação, onde todos os elementos entendidos como forças externas e internas são reunidos, sem contar, necessariamente, com a existência de um departamento ou outro grupamento qualquer, formalmente instituído para gerar inovações. O caráter ocasional das relações estabelecidas no interior deste sistema os leva a concluir, no entanto, que os sistemas de inovação em serviços são adocráticos, ou seja, como definimos anteriormente, são sistemas mediados prioritariamente pelo mercado, por meio do mecanismo de preços, e possuem, assim, um componente operacional predominante em relação aos componentes estratégicos vigentes nas relações de cooperação observadas em sistemas manufatureiros. 
Este caráter adocrático não permite, no entanto, descuidar a importância que as especificidades locais jogam no processo de inovação em serviços. Em especial não permite desconhecer a presença de um processo de aprendizagem coletiva regional, definido por Lorenz como "... a criação e o desenvolvimento de uma base de conhecimento comum ou compartilhado entre os indivíduos constituindo um sistema produtivo que lhes permita coordenar suas ações na resolução de problemas tecnológicos e organizacionais com que eles se confrontam" (como citado em Keeble \& Wilkinson, 1999, p. 296). Este processo está na essência do setor de serviços pela relevância das relações usuário-produtor. Como vimos, Lundvall aponta como estas relações estão cultural e localmente delimitadas, o que implica o ritmo e direção do processo de inovação. A pertinência desta abordagem sistêmica e de sua conformação espacial é um dos pontos de contato mais importantes na perspectiva de integração de uma teoria da inovação que congregue indústria e serviços.

Sundbo e Gallouj (1998a), no entanto, estenderam sua visão de uma relação assistemática para sua análise da dimensão espacial e concluíram que os sistemas e subsistemas de inovação verificados em serviços não possuem uma dimensão sequer nacional, podendo ser compreendidos apenas como sistemas internacionais e que a internacionalização está intimamente ligada ao seu potencial inovador.

\section{Sistemas de Inovação Centrado em Problemas ou Oportunidades}

Tether e Metcalfe (2004) propuseram uma aplicação do conceito de sistemas setoriais de inovação a determinados ramos de serviços. Este esforço parte de uma adaptação inicial do conceito de Malerba $(2002$; 2004) que, como vimos, ancora o sistema setorial em torno de um produto. Segundo os autores, a impossibilidade de identificar, a priori, um produto do serviço, dada a dificuldade de distinguir processo e produto na prestação de serviços, os conduz a propor a articulação de sistemas setoriais de serviços em torno de problemas ou oportunidades identificadas. Em suas palavras, problemas e oportunidades "não necessariamente definem as soluções, ou o padrão de solução, mas as contingências provavelmente restringem o escopo das soluções possíveis" (Tether $\&$ Metcalfe, 2004, p. 318).

Os autores analisaram três casos de inovações segundo esta ótica. No primeiro, avaliaram a necessidade de expansão da capacidade de aeroportos em face da impossibilidade de sua ampliação. Centraram suas atenções em inovações introduzidas no serviço de controle de vôo, que permitiram que estes aeroportos, alguns dos mais concorridos do mundo - a saber, Frankfurt, London Heathrow e 
London Gatewick - ampliassem seu fluxo de aterrissagens e decolagens sem ampliação de suas pistas. No segundo caso, os autores debruçaram-se na evolução de um serviço de saúde considerado dos mais requisitados, os serviços oftalmológicos, mais especificamente a intervenção para solução do problema de cataratas, a partir da introdução das lentes intra-oculares. Neste ponto os autores enfatizam como a introdução destas lentes movimentou setores industriais e de serviços, conduziu modificações nos procedimentos médicos e provocou um deslocamento geográfico do processo de inovação, que iniciara nos hospitais europeus, com a atuação dos médicos, se tornou uma atividade majoritariamente desenvolvida pelas grandes multinacionais norte-americanas fabricantes de equipamentos médico-hospitalares.

Nestes dois primeiros casos, é possível perceber como vários agentes econômicos e institucionais se envolveram nos processos, visto que tanto o tráfego aéreo quanto os serviços médicos, em diferentes proporções, estão submetidos a fortes regulamentações. Mais do que isso se pode observar como a evolução dos processos de inovação esteve diretamente relacionada com o desenvolvimento de todos estes agentes, engendrando importantes laços co-operativos e corroborando a tese evolucionária, interpretada por Malerba, de que o processo de inovação é um processo de co-evolução.

O último caso se refere ao setor supermercadista e analisa os efeitos das inovações nos serviços de distribuição sobre a organização do setor, estabelecendo uma comparação entre o caso britânico e o caso sueco. Esse estudo comparativo permitiu ressaltar as influências institucionais na definição das trajetórias de inovação que o processo de distribuição assumiu diversamente nos dois países. Mesmo assim, Tether e Metcalfe, que observam a presença de diferentes intervenientes de acordo com a dimensão espacial considerada, não levam adiante esta análise, pois a falta de um produto definido do serviço, segundo os autores, impediu uma análise comparativa mais esclarecedora.

Esta construção de um sistema de inovação em torno de problemas ou oportunidades, em substituição ao produto, por sua vez aponta um nível microssistêmico de análise, onde, ao invés do foco estar no setor como um todo, ele está direcionado para a prestação de um serviço específico, intra-setorial, analisando a trajetória das inovações desenvolvidas para solucionar os problemas deste serviço. Neste nível, as organizações que prestam serviços finais são o foco mais importante, pois são estas que podem combinar todas as contribuições voltadas para a solução do problema específico. Mesmo com esta opção analítica, fica evidente, também nesta perspectiva, a importância do processo de aprendizagem na construção das inovações, pois a atividade de resolução de problemas é a própria organizadora do conjunto do sistema. 


\section{Limites e Perspectivas das Análises Sistêmicas do Processo de Inovação em Serviços: em Busca de um Modelo}

As abordagens teóricas analisadas nas seções anteriores apontam a possibilidade de um enfoque integrador que, à luz da noção de sistemas de inovação, permita considerar não apenas o processo de inovação no setor manufatureiro, mas também o processo de inovação no setor de serviços. Parece compatível, ainda, que um enfoque como tal aponte a pertinência de uma dimensão espacial na consideração destes processos de inovação.

No entanto, para que esta perspectiva se concretize, algumas questões precisam ser revistas, principalmente no que tange à incorporação dos serviços. Em primeiro lugar, há a necessidade de uma redefinição do enfoque sistêmico, para contemplar adequadamente a heterogeneidade e as especificidades dos serviços, o que passa pela definição do seu nível e objeto de análise. Segundo, torna-se necessário discutir, a partir destas definições, a relevância ou não de considerações de caráter espacial para análise do processo de inovação, sobretudo em serviços, questão esta em que o processo de aprendizagem joga papel fundamental.

As aplicações empíricas da abordagem sistêmica no setor de serviços, que pudemos descrever, trouxeram à tona insuficiências importantes. Embora estas aplicações não possam ser consideradas definitivas, alguns pontos podem ser desde já revistos para orientar novas investigações.

Assim, a análise de Sundbo e Gallouj (1998a), que conclui pela existência de sistemas de inovação adocráticos em serviços, apresenta duas fragilidades importantes. Por um lado, esta abordagem, cuja origem é justamente o intuito de resgatar o lugar dos serviços na teoria da inovação, adota em suas análises um conceito global de setor de serviços como se este constituísse um conjunto homogêneo. Desta forma, considerando a variabilidade entre as atividades de serviço, dificilmente os autores poderiam encontrar padrões similares de inovação ao longo de todo o setor, o que foi definido como um padrão adocrático ou, em outras palavras, um não-sistema.

$\mathrm{Na}$ verdade, o setor de serviços precisa ser considerado, assim como a manufatura o é, como um conjunto de subsetores de serviços, cada qual desenvolvendo sua própria dinâmica de inovação. Por outro lado, este mesmo caráter adocrático justifica a conclusão seguinte dos autores sobre a impossibilidade de estabelecer um vínculo sistêmico com alguma dimensão espacial do processo de inovação. Terminando, assim, por apontar o crescente grau de internacionalização presente nos serviços como o indício de que este vínculo não teria senso analítico. 
Esta característica, entretanto, não pode ser considerada definitiva na análise da pertinência de considerações do tipo espacial. Pelo contrário, a internacionalização expande a possibilidade de reprodução de um ambiente inovador constituído em fortes bases locais, mas que obtém conhecimento de fontes externas, garantindo sua atualidade. Como afirmam Keeble e Wilkinson (1999), "aprender de fontes externas de conhecimento é, portanto, um ingrediente essencial para o sucesso continuado de um ambiente inovador" (p. 299). O processo de aprendizagem, embora inserido numa dinâmica internacional, sob o paradigma da economia do aprendizado, apresenta fortes contornos locais, culturais e institucionalmente definidos que muitas vezes o condicionam e que têm sido destacados por vários autores (Leamer \& Storper, 2001; Moulaert \& Gallouj, 1993; Simmie \& Sennett, 1999).

Esta relação entre dimensão espacial e processo de aprendizagem, produzindo seus efeitos no processo de inovação, foi identificada nos casos estudados sob o conceito de sistema setorial (Tether \& Metcalfe, 2004), embora de forma não conclusiva. Estes mesmos estudos, evidenciaram o protagonismo do processo de aprendizagem na articulação do sistema setorial e no próprio resultado do processo de inovação em serviços. Entretanto Tether e Metcalfe (2004) abdicam de realizar uma aplicação integral do conceito de sistema setorial de inovação como proposto por Malerba $(2002 ; 2004)$, ao retirarem do centro de sua configuração sistêmica o produto do serviço e subsituí-lo pela noção de problema a ser resolvido ou de oportunidade a ser aproveitada. Neste sentido, a aplicação foi prejudicada, impedindo a caracterização estrutural do sistema setorial e o tratamento de uma questão tão relevante quanto a especificidade intersetorial dos serviços.

Podemos considerar, no entanto, no que diz respeito a integração dos serviços e de suas especificidades, que a abordagem setorial contribui decisivamente para a análise do processo de inovação em serviços, propiciando que ramos dos serviços tão distintos como os serviços de assistência médica, de transporte aéreo, de consultoria, de educação, de telefonia, para citar alguns exemplos, possam ser analisados segundo suas características específicas. Contudo, para que a configuração destes setores possa efetivamente ser realizada, o nível de análise originalmente proposto por Malerba $(2002$; 2004) precisa ser retomado, qual seja, o nível do produto. A busca de soluções de problemas específicos ou de formas de usufruir de oportunidades determinadas, ensejando processos de aprendizagem como os descritos por Tether e Metcalfe (2004), podem ser elementos importantes na estruturação da configuração setorial, mas não podem esgotar a caracterização de um setor de serviços.

Esta aplicação do conceito de sistema setorial de inovação em serviços precisa 
romper, ainda, com a oposição entre lógica espacial e lógica setorial. Como o próprio Malerba (2002) aponta, há influências de instituições organizadas em lógicas espaciais (nacionais, regionais ou locais) sobre a dinâmica setorial. Se, por um lado, isto não deve ofuscar a lógica internacional, ou global, que incide sobre o sistema de inovação, por outro não permite que sejam negligenciadas as variáveis de caráter espacial definidas, como aspectos geográficos, culturais e regulatórios, por exemplo, que interferem na dinâmica do processo de aprendizagem e, portanto, na evolução da base de conhecimento de um sistema setorial.

A esta perspectiva associa-se uma das principais características dos serviços, o seu caráter relacional, em que a interação do usuário com o provedor de um serviço assume papel central. Há, assim, na busca de uma aplicação diferenciada do conceito de sistema setorial de inovação aos serviços, combinada com a caracterização do produto de cada atividade de serviço setorialmente definida, um caminho para apreender a dinâmica do processo de aprendizagem e, a partir de seus condicionantes setorialmente identificados, a dimensão espacial relevante no processo de inovação considerado.

\section{Considerações Finais}

A lacuna existente entre a importância do setor de serviços, por um lado, e os esforços teóricos destinados a compreendê-la, de outro, passo a passo vai sendo preenchida. As abordagens teóricas sobre a inovação em serviços já acumulam evidências empíricas que não permitem mais nenhuma dúvida sobre a capacidade inovadora das organizações do setor de serviços e, sobretudo, sob o caráter majoritariamente endógeno destas inovações.

No entanto questões colocadas pelo paradigma da economia do aprendizado, como a centralidade do processo de aprendizagem, ainda precisam ser integradas em uma abordagem teórica que responda ao esforço de construção de uma teoria da inovação que reconcilie bens e serviços e, ao mesmo tempo, permita que o setor de serviços seja analisado em suas especificidades e em sua heterogeneidade.

Este artigo, ainda que distante de constituir esta referida abordagem, se insere no esforço de sua construção. Procuramos articular aqui a abordagem dos sistemas de inovação e a teoria da inovação em serviços, tendo em conta, como elementos centrais, o processo de aprendizagem e seus condicionantes, especialmente culturais e geográficos, o que nos remeteu a discussão da pertinência de uma dimensão espacial no processo de inovação. 
Após uma revisão da literatura que considerou as principais abordagens sobre a inovação em serviços e a abordagem dos sistemas de inovação, analisamos os principais trabalhos empíricos que articulam estas duas vertentes.

O caminho percorrido nos permitiu algumas constatações. Primeiro, as abordagens sistêmicas aplicadas ao setor de serviços, seja por permitirem que uma visão homogênea dos serviços sobressaísse, seja por adotarem um nível de análise microssetorial, não permitem uma análise do processo de inovação que esteja adequada às especificidades intersetoriais dos serviços. Segundo, como decorrência da falta de uma caracterização setorial precisa, ofuscaram a possibilidade de compreensão dos processos de aprendizagem subjacentes. Estes, por sua vez, por suas características muitas vezes definidas localmente, graças a variáveis geográficas, institucionais e culturais, constituem os elementos centrais para a discussão sobre a pertinência de uma dimesnão espacial inserida nestas análises sistêmicas.

A partir dessas críticas, propomos que a abordagem mais apropriada para analisar a inovação em serviços sob o paradigma da economia do aprendizado está relacionada com o conceito de sistema setorial de inovação. Este, no entanto, precisa ser adaptado ao setor de serviços, levando em conta sua heterogeneidade e, especialmente, dois aspectos: o caráter relacional dos serviços, onde a interação usuário-produtor e todo o processo de aprendizagem envolvido jogam papel central, e a própria definição do produto do serviço, como articuladora de cada um dos sistemas setoriais de serviços. Podemos vislumbrar, assim, a postulação dos elementos teóricos fundamentais para a compreensão do processo de aprendizagem, do seu resultado primoridal, a inovação, e verificar a influência das variáveis espaciais nesta dinâmica. Estas considerações, portanto, devem ser levadas a termo em futuras investigações empíricas.

\section{Artigo recebido em 06.04.2004. Aprovado em 12.04.2005.}

\section{Notas}

1. Sundbo e Gallouj (1998a) utilizam o termo loosely coupled system. Por conveniência, e resguardando o sentido original, entendemos que o termo adocrático, ou contingencial, ou, ainda, sistema ad hoc são os que podem representar a melhor tradução.

${ }^{2}$. Os dados que sustentam a análise de Sundbo e Gallouj resultam do projeto SI4S (Services for Innovation - Innovation for Services), sob coordenação do Step Group, de Oslo, Noruega. O projeto reuniu onze grupos de pesquisa, de 10 países. Seus dados provêm de surveys realizadas na Dinamarca, França e Noruega, envolvendo diferentes ramos de serviços, entrevistas com especialistas e análises dos dados macroeconômicos disponíveis. 


\section{Referências Bibliográficas}

Barras, R. (1986, August).

Towards a theory of innovation in services. Research Policy, 15(4), 161173.

Dosi, G. (1982, June).

Technological paradigms and technological trajectories. Research Policy, 11(3), 147-162.

Freeman, C.; \&

Perez, C (1988).

Structural crises of adjustment: business cycles and investment behaviour. In: G. Dosi, R. Nelson, G. Silverberg, \& L. Soete, (Eds). Technical change and economic theory (pp.38-66). London: Printer Publishers.

Freeman, C (1995, January).

The national innovation system in a historical perspective. Cambridge Journal of Economics, 19(1), 5-24.

Gallouj, F. (1997, December).

Towards a neo-Schumpeterian theory of innovation in services? Science and Public Policy, 24(6), 405-420.

Gallouj, F. (1998).

Innovating in reverse: services and the reverse product cycle. European Journal of Innovation Management, 1(3), 123-138.

Hauknes, J. (1996).

Innovation in the service economy (Step report, n.7). Oslo, Noruega. Recuperado em 27 outubro, 2005, de http://www.step.no/old/Projectarea/ si4s/index.htm.
Hauknes, J. (1998).

Services in innovation - innovation in services (Step report, n.13). Oslo, Noruega. Recuperado em 27 outubro, 2005, de http://www.step.no/old/ Projectarea/si4s/index.htm

Keeble, D., \&

Wilkinson, F. (1999, June).

Collective learning and knowledge development in the evolution of regional clusters of high technology SMEs in Europe. Regional Studies, 33(4), 295-303.

Lakshmanan, T. R (1989).

Technological and institutional innovations in the service sector. In: A. E Andersson, D. F. Batten, \& C. Karlsson, (Eds). Knowledge and Industrial Organization (pp.63-79). Berlin: Springer-Verlag.

Lastres, H.,

Cassiolato, J.,

Lemos, C.,

Maldonado, J., \&

Vargas, M. (1998).

Globalização e inovação localizada (Nota técnica n.1). Rio de Janeiro, RJ: Instituto de Economia/ UFRJ.

Leamer, E. E., \&

Storper, M. (2001).

The economic geography of the internet age. Journal of International Business Studies ,32(4), 641-665. 
Lundvall, B. A. (1988).

Innovation as an interactive process: from user-producer interaction to the national system of innovation. In: G. Dosi, R. Nelson, G. Silverberg, \& L. Soete, (Eds). Technical change and economic theory (pp.349-369). London: Printer Publishers.

Lundvall, B. A. (1998, December).

Why study national systems and national styles of innovation? Technology Analysis \& Strategic Management, 10(4), 407-421.

Malerba, F. (2002, February).

Sectoral systems of innovation and production. Research Policy, 31(2), 247-264.

Malerba, F. (Ed). (2004).

Sectorial systems of innovation: concepts, issues and analyses of six major sectors in Europe. Cambridge: Cambridge University Press.

Moulaert, F., \&

Gallouj, C. (1993, April).

The locational geography of advanced producer service firms: the limits of economies of agglomeration. The Services Industries Journal, 13(2), 91-106.

Nelson, R. (1988).

Institutions supporting technical change in the United States. In: G. Dosi, R. Nelson, G. Silverberg, \& L. Soete, (Eds).. Technical change and economic theory (pp.312-329). London: Printer Publishers.
Schumpeter, J. (1985).

A teoria do desenvolvimento econômico. São Paulo: Nova Cultural.

Simmie J., \&

Sennett, J. (1999, October).

Innovative clusters: global or local linkages? National Institute Economic Review, 170, pp.87-98.

Sundbo, J., \&

Gallouj, F. (1998a).

Innovation as a loosely coupled system in services (SI4S Topical Paper, n.4). Oslo, Noruega. Recuperado em 27 outubro, 2005, de http://www.step.no/old/Projectarea/ si4s/index.htm.

Sundbo, J., \&

Gallouj, F. (1998b).

Innovation in services (SI4S Synthesis Paper, n.2). Oslo, Noruega. Recuperado em 27 outubro, 2005, de http://www.step.no/old/Projectarea/ si4s/index.htm.

Tether, B. S., \&

Metcalfe, J. S. (2004).

Services and systems of innovation. In: F. Malerba, (Ed). Sectorial systems of innovation: concepts, issues and analyses of six major sectors in Europe (pp. 287-321). Cambridge: Cambridge University Press.

Zawislak, P. (1996).

Uma abordagem evolucionária para a análise de casos de atividade de inovação no Brasil. Ensaios FEE, 17(1), 323-354. 
